\title{
Solubility Data, Solubility Parameters and Thermodynamic Behavior of an Antiviral Drug Emtricitabine in Different Pure Solvents: Molecular Understanding of Solubility and Dissolution
}

\author{
Faiyaz Shakeel (D, Nazrul Haq, Ibrahim Alsarra (D) and Sultan Alshehri * (D) \\ Department of Pharmaceutics, College of Pharmacy, King Saud University, P.O. Box 2457, \\ Riyadh 11451, Saudi Arabia; faiyazs@fastmail.fm (F.S.); nazrulhaq59@gmail.com (N.H.); \\ ialsarra@ksu.edu.sa (I.A.) \\ * Correspondence: salshehri1@ksu.edu.sa
}

check for

updates

Citation: Shakeel, F.; Haq, N.; Alsarra, I.; Alshehri, S. Solubility Data, Solubility Parameters and Thermodynamic Behavior of an Antiviral Drug Emtricitabine in Different Pure Solvents: Molecular Understanding of Solubility and Dissolution. Molecules 2021, 26, 746 https://doi.org/10.3390/

molecules26030746

Academic Editors: Christian Silvio Pomelli and Andrea Mezzetta Received: 2 January 2021

Accepted: 28 January 2021

Published: 31 January 2021

Publisher's Note: MDPI stays neutral with regard to jurisdictional claims in published maps and institutional affiliations.

Copyright: (c) 2021 by the authors. Licensee MDPI, Basel, Switzerland. This article is an open access article distributed under the terms and conditions of the Creative Commons Attribution (CC BY) license (https:// creativecommons.org/licenses/by/ $4.0 /)$.

\begin{abstract}
The solubility values, various Hansen solubility parameters (HSPs) and thermodynamic behavior of emtricitabine (ECT) in twelve different pure solvents (PS) were estimated using various experimental as well as computational methods. Experimental solubility values $\left(x_{\mathrm{e}}\right)$ of ECT in twelve different PS were obtained at $T=298.2 \mathrm{~K}$ to $318.2 \mathrm{~K}$ and $p=0.1 \mathrm{MPa}$. The $x_{\mathrm{e}}$ values of ECT were correlated by "van't Hoff, Apelblat and Buchowski-Ksiazaczak $\lambda h$ models". Various HSPs for ECT and twelve different PS were also calculated using "HSPiP software". The $x_{\mathrm{e}}$ values of ECT were estimated maximum in polyethylene glycol-400 (PEG-400; $1.41 \times 10^{-1}$ ), followed by ethylene glycol, Transcutol-HP, propylene glycol, methanol, water, isopropanol, ethanol, 1-butanol, dimethyl sulfoxide, 2-butanol and EA $\left(1.28 \times 10^{-3}\right)$ at $T=318.2 \mathrm{~K}$. "Apparent thermodynamic analysis" showed an "endothermic and entropy-driven dissolution" of ECT. Overall, PEG-400 was found as the best/ideal solvent for solubility/miscibility of ECT compared to other solvents studied.
\end{abstract}

Keywords: dissolution; emtricitabine; molecular understanding; solubility; solubility parameter; thermodynamics

\section{Introduction}

Emtricitabine (ECT, Figure 1; chemical name: 4-amino-5-fluoro-1-[(2R,5S)-2(hydroxymethyl)-1,3-oxathiolan-5-yl]pyrimidin-2-one; molecular formula: $\mathrm{C}_{8} \mathrm{H}_{10} \mathrm{FN}_{3} \mathrm{O}_{3} \mathrm{~S}$; molar mass: $247.24 \mathrm{~g} \mathrm{~mol}^{-1}$, CASRN: 143491-57-0 and PubChem CID: 60877) occurs as a white to off white powder [1,2].<smiles>Nc1nc(=O)n([C@H]2CS[C@@H](CO)O2)cc1F</smiles>

Figure 1. Molecular structure of emtricitabine (ECT) (molar mass: $247.24 \mathrm{~g} \mathrm{~mol}^{-1}$ ).

It is a synthetic nucleoside analog which is active against human immunodeficiency virus type I (HIV-I) reverse transcriptase [2,3]. It is used alone or in combination with other antiviral drugs in the treatment of HIV-I-infected patients [3-5]. ECT is commercially available as capsules or oral solutions by the brand name of Emtriva ${ }^{\circledR}$ for the treatment of HIV-I-infected patients [2,5]. It is reported as freely soluble in water at $T=298.2 \mathrm{~K}$ [2]. ECT is highly water-soluble drug and hence rapidly and extensively absorbed following oral administration of capsules or oral solutions [5]. The absolute bioavailability of 
Emtriva ${ }^{\circledR}$ capsules and Emtriva ${ }^{\circledR}$ solution have been reported as $93 \%$ and $75 \%$, respectively [2]. The relative bioavailability of Emtriva ${ }^{\circledR}$ oral solutions has been reported as approximately $80 \%$ compared with capsules [2]. Various dosage form strategies such as solid dosage form [4,6-8], semi-solid gels [9], vesicle-based drug delivery system [10], microparticulate-based drug delivery system [11] and nanotechnology-based drug delivery systems [5,12-15] have been investigated in literature to improve its antiviral therapy. The quantitative solubility value of ECT in water has been reported as $112 \mathrm{mg} \mathrm{mL}^{-1}$ at $T=298.2 \mathrm{~K}$ [2]. Recently, the solubility values of ECT in mole fraction in neat water, neat polyethylene glycol-400 (PEG-400) and various (PEG-400 + water) mixtures at $T=298.2 \mathrm{~K}$ to $318.2 \mathrm{~K}$ and $p=0.1 \mathrm{MPa}$ have been reported in literature [16]. While, temperaturedependent solubilities and other physicochemical parameters of ECT in other studied solvents are not reported elsewhere. The solubility and other physicochemical data of drugs in pure solvents have significant role in drug discovery process and formulation development [17-19]. Although, ECT had no solubility issues but the solubility and other physicochemical data of ECT are scarce in literature. ECT is a BCS class I drug but solubility data are important for any kind of drug in order to obtain the physicochemical information about those drugs $[4,17]$. The solubility data of drugs are important for various industrial processes such as purification, recrystallization, drug development, drug discovery, preformulation studies and formulation development $[18,19]$. Because the solubility data of ECT in most of the studied solvents is not reported in literature, this drug was chosen for this study. Therefore, the solubility values of ECT in various pure solvents (PS) namely "water, methanol, ethanol, isopropanol (IPA), 1-butanol, 2-butanol, ethylene glycol (EG), propylene glycol (PG), PEG-400, Transcutol-HP (THP), ethyl acetate (EA) and dimethyl sulfoxide (DMSO)" at $T=298.2 \mathrm{~K}$ to $318.2 \mathrm{~K}$ and $p=0.1 \mathrm{MPa}$ were obtained using a saturation shake flask method. The solubility studies were carried out at different temperature under atmospheric pressure. The influence of pressure on ECT solubility was not performed in this study. The value of atmospheric pressure was not measure/maintained as the influence of pressure on solubility was not studied. The control of atmospheric pressure is not important in such cases. Normal and three-dimensional Hansen solubility parameters were calculated to select the best solvents for ECT. "Apparent thermodynamic analysis" was conducted to study dissolution behavior of ECT. The molecular interactions between ECT and various PS were also evaluated. The solubility values, solubility parameters and other physicochemical data of ECT obtained in this study would be useful in "purification, recrystallization, drug discovery, pre-formulation studies and formulation development" of ECT.

\section{Results and Discussion}

\subsection{Solid Phase Characterization of ECT}

The solid phase characterization of ECT in pure and equilibrated sample was conducted using a differential scanning calorimetry (DSC) analysis. The representative DSC curves of pure and equilibrated ECT are given in Figure 2. The DSC curve of pure ECT showed a sharp crystalline peak at fusion temperature $\left(T_{\text {fus }}\right)=154.60{ }^{\circ} \mathrm{C}$ (converted to $427.80 \mathrm{~K})$. The fusion enthalpy $\left(\Delta H_{\text {fus }}\right)$ and heat capacity difference $\left(\Delta C_{\mathrm{p}}\right)$ values of pure ECT were recorded as $32.37 \mathrm{~kJ} \mathrm{~mol}^{-1}$ and $75.66 \mathrm{~J} \mathrm{~mol}^{-1} \mathrm{~K}^{-1}$, respectively. The DSC curve of equilibrated ECT also showed a sharp crystalline peak at $T_{\text {fus }}=154.75^{\circ} \mathrm{C}$ (converted to $427.95 \mathrm{~K}$ ). The $\Delta H_{\text {fus }}$ and $\Delta C_{\mathrm{p}}$ values of equilibrated ECT were recorded as $31.75 \mathrm{~kJ} \mathrm{~mol}^{-1}$ and $74.19 \mathrm{~J} \mathrm{~mol}^{-1} \mathrm{~K}^{-1}$, respectively. The DSC curves and various thermal parameters (i.e., $T_{\text {fus }}, \Delta H_{\text {fus }}$ and $\Delta C_{\mathrm{p}}$ ) of pure and equilibrated ECT were not varied significantly $(p>0.05)$, suggesting that ECT exists in pure crystalline form which was not transformed into polymorphs/hydrates/solvates after solubility experiments $[18,20]$. In addition, the X-ray diffraction (XRD) patterns of pure and equilibrated ECT were also found to be similar in our previous publication [16]. Hence, the DSC spectra of present study and XRD patterns of our previous publication suggested no transformation of ECT into different forms. Because the physical form of ECT remained unchanged from the sample recovered 
from ethanol, it was expected that its physical form will also be remain unchanged if the sample will be recovered from some other PS such as methanol, IPA, PEG-400, THP, water etc. The $T_{\text {fus }}$ of ECT was recorded as $156.90^{\circ} \mathrm{C}$ (converted to $430.10 \mathrm{~K}$ ) by Srilatha et al. [6]. Fathima et al. found the $T_{\text {fus }}$ of ECT as $153.40^{\circ} \mathrm{C}$ (converted to $426.60 \mathrm{~K}$ ) [11]. The $T_{\text {fus }}$ of pure ECT was obtained as $154.60{ }^{\circ} \mathrm{C}$ (converted to $427.80 \mathrm{~K}$ ) in the present work which was very close with those reported in literature $[6,11]$.

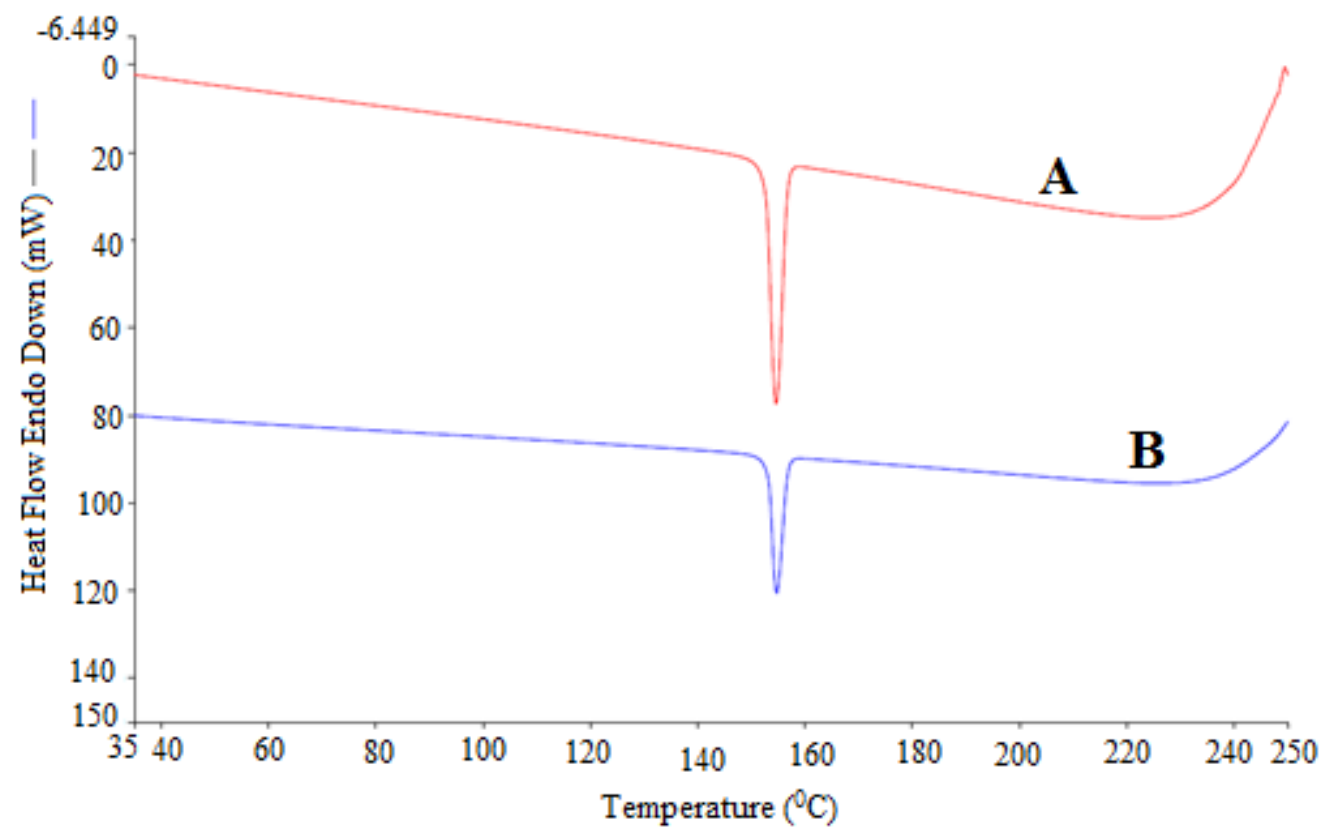

Figure 2. DSC spectra of (A) pure ECT and (B) equilibrated ECT (recovered from ethanol).

\subsection{Solubility Data of ECT Using Experimental Approach and Comparison with Literature}

The experimental mole fraction solubility $\left(x_{\mathrm{e}}\right)$ values of ECT in twelve different PS at $T=298.2 \mathrm{~K}$ to $318.2 \mathrm{~K}$ and $p=0.1 \mathrm{MPa}$ were obtained by applying Equation (1) and results are listed in Table 1.

Table 1. Experimental solubilities $\left(x_{\mathrm{e}}\right)$ of emtricitabine (ECT) in mole fraction in various pure solvents (PS) at $T=298.2 \mathrm{~K}$ to $318.2 \mathrm{~K}$ and $p=0.1 \mathrm{MPa}^{\mathrm{a}}$.

\begin{tabular}{|c|c|c|c|c|c|}
\hline \multirow{2}{*}{ PS } & \multicolumn{5}{|c|}{$x_{e}$} \\
\hline & $T=298.2 \mathrm{~K}$ & $T=303.2 \mathrm{~K}$ & $T=308.2 \mathrm{~K}$ & $T=313.2 \mathrm{~K}$ & $T=318.2 \mathrm{~K}$ \\
\hline EA & $3.63 \times 10^{-4}$ & $5.34 \times 10^{-4}$ & $7.12 \times 10^{-4}$ & $9.96 \times 10^{-4}$ & $1.28 \times 10^{-3}$ \\
\hline 2-Butanol & $2.43 \times 10^{-3}$ & $2.98 \times 10^{-3}$ & $3.94 \times 10^{-3}$ & $5.07 \times 10^{-3}$ & $6.55 \times 10^{-3}$ \\
\hline DMSO & $2.56 \times 10^{-3}$ & $3.15 \times 10^{-3}$ & $4.09 \times 10^{-3}$ & $5.34 \times 10^{-3}$ & $6.59 \times 10^{-3}$ \\
\hline 1-Butanol & $2.89 \times 10^{-3}$ & $3.46 \times 10^{-3}$ & $4.32 \times 10^{-3}$ & $5.36 \times 10^{-3}$ & $6.84 \times 10^{-3}$ \\
\hline Ethanol & $3.82 \times 10^{-3}$ & $4.54 \times 10^{-3}$ & $5.31 \times 10^{-3}$ & $6.29 \times 10^{-3}$ & $7.76 \times 10^{-3}$ \\
\hline IPA & $3.95 \times 10^{-3}$ & $4.64 \times 10^{-3}$ & $5.58 \times 10^{-3}$ & $6.76 \times 10^{-3}$ & $8.19 \times 10^{-3}$ \\
\hline Water & $8.02 \times 10^{-3}$ & $8.66 \times 10^{-3}$ & $9.45 \times 10^{-3}$ & $1.03 \times 10^{-2}$ & $1.13 \times 10^{-2}$ \\
\hline Methanol & $1.08 \times 10^{-2}$ & $1.17 \times 10^{-2}$ & $1.26 \times 10^{-2}$ & $1.38 \times 10^{-2}$ & $1.49 \times 10^{-2}$ \\
\hline PG & $3.18 \times 10^{-2}$ & $3.27 \times 10^{-2}$ & $3.47 \times 10^{-2}$ & $3.67 \times 10^{-2}$ & $3.90 \times 10^{-2}$ \\
\hline THP & $3.20 \times 10^{-2}$ & $3.45 \times 10^{-2}$ & $3.81 \times 10^{-2}$ & $4.10 \times 10^{-2}$ & $4.65 \times 10^{-2}$ \\
\hline EG & $4.66 \times 10^{-2}$ & $4.87 \times 10^{-2}$ & $5.12 \times 10^{-2}$ & $5.39 \times 10^{-2}$ & $5.72 \times 10^{-2}$ \\
\hline PEG-400 & $1.09 \times 10^{-1}$ & $1.15 \times 10^{-1}$ & $1.23 \times 10^{-1}$ & $1.32 \times 10^{-1}$ & $1.41 \times 10^{-1}$ \\
\hline$x^{\mathrm{idl}}$ & $3.74 \times 10^{-2}$ & $4.35 \times 10^{-2}$ & $5.05 \times 10^{-2}$ & $5.85 \times 10^{-2}$ & $6.76 \times 10^{-2}$ \\
\hline
\end{tabular}

a The relative uncertainties $u_{\mathrm{r}}$ are $u_{\mathrm{r}}(T)=0.013, u_{\mathrm{r}}(p)=0.003$ and $u_{\mathrm{r}}\left(x_{\mathrm{e}}\right)=0.014$.

The solubility of ECT in water at $T=298.2 \mathrm{~K}$ is reported elsewhere [2]. The mole fraction solubility values of ECT in water, PEG-400 and various (PEG-400 + water) mixtures 
at $T=298.2 \mathrm{~K}$ to $318.2 \mathrm{~K}$ and $p=0.1 \mathrm{MPa}$ have also been reported in our previous article [16]. However, the quantitative solubility values of ECT in other investigated PS are not reported elsewhere. The solubility of ECT in water at $T=298.2 \mathrm{~K}$ has been reported as $112 \mathrm{mg} / \mathrm{mL}$ (converted to $8.09 \times 10^{-3}$ in mole fraction) [2]. The temperature dependent solubility data of ECT in any of the investigated PS are not reported by other researchers. Hence, we compared the temperature dependent experimental solubility data of ECT in neat water and neat PEG-400 with those reported in our previous publication. The mole fraction solubility values of ECT in water at $T=298.2 \mathrm{~K}$ to $318.2 \mathrm{~K}$ and $p=0.1 \mathrm{MPa}$ have been reported in the range of $7.95 \times 10^{-3}$ to $1.15 \times 10^{-2}$ in our previous publication [16]. The mole fraction solubility of ECT in water at $T=298.2 \mathrm{~K}$ was calculated as $8.02 \times 10^{-3}$ in the present work. The mole fraction solubility values of ECT in water at $T=298.2 \mathrm{~K}$ to $318.2 \mathrm{~K}$ and $p=0.1 \mathrm{MPa}$ were calculated in the range of $8.02 \times 10^{-3}$ to $1.13 \times 10^{-2}$ in the present work. The mole fraction solubility values of ECT in PEG-400 at $T=298.2 \mathrm{~K}$ to $318.2 \mathrm{~K}$ and $p=0.1 \mathrm{MPa}$ have been reported in the range of $1.06 \times 10^{-1}$ to $1.45 \times 10^{-1}$ in our previous publication [16]. The mole fraction solubility values of ECT in PEG-400 at $T=298.2 \mathrm{~K}$ to $318.2 \mathrm{~K}$ and $p=0.1 \mathrm{MPa}$ were calculated in the range of $1.09 \times 10^{-1}$ to $1.41 \times 10^{-1}$ in the present work. The graphical correlation between experimental and literature solubility values of ECT in water (Figure 3A) and PEG-400 (Figure 3B) at $T=298.2 \mathrm{~K}$ to $318.2 \mathrm{~K}$ is summarized in Figure 3. The results summarized in Figure 3 suggested good correlation of experimental solubility values of ECT with its literature values. Overall, the solubility values of ECT in water and PEG-400 recorded in this work were found to be very close with those reported in literature $[2,16]$.
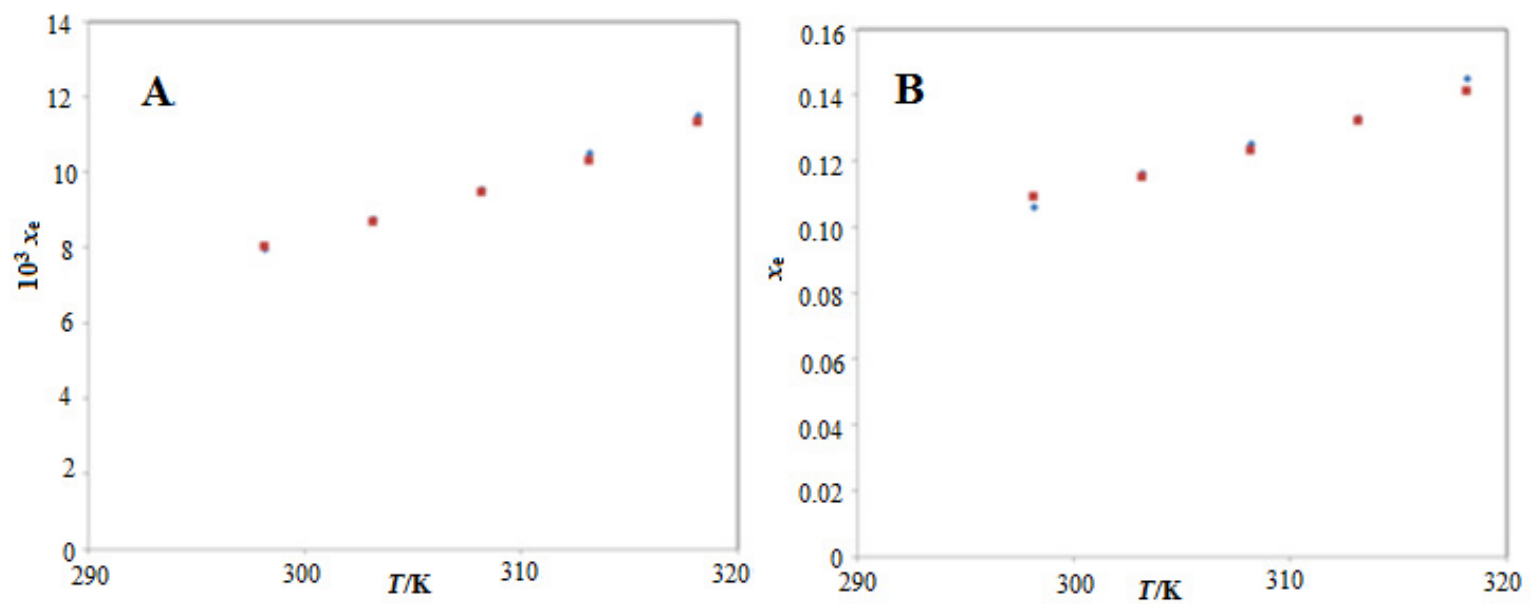

Figure 3. Comparison of mole fraction solubility values of ECT in (A) water and (B) PEG-400 with literature values at $T=298.2 \mathrm{~K}$ to $318.2 \mathrm{~K}$; the symbol $\square$ indicates the experimental mole fraction solubilities of ECT in (A) water and (B) PEG-400 and the symbol indicates the literature solubilities of ECT in (A) water and (B) PEG-400 taken from reference [16].

The solubility values listed in Table 1 showed that the $x_{\mathrm{e}}$ values of ECT were found to be increasing significantly with the raise in temperature in all PS evaluated $(p<0.05)$. The $x_{\mathrm{e}}$ values of ECT were found highest in PEG-400 $\left(1.41 \times 10^{-1}\right)$, followed by EG $\left(5.72 \times 10^{-2}\right)$, THP $\left(4.65 \times 10^{-2}\right)$, PG $\left(3.90 \times 10^{-2}\right)$, methanol $\left(1.49 \times 10^{-2}\right)$, water $\left(1.13 \times 10^{-2}\right)$, IPA $\left(8.19 \times 10^{-3}\right)$, ethanol $\left(7.76 \times 10^{-3}\right)$, 1-butanol $\left(6.84 \times 10^{-3}\right)$, DMSO $\left(6.59 \times 10^{-3}\right)$, 2butanol $\left(6.55 \times 10^{-3}\right)$ and EA $\left(1.28 \times 10^{-3}\right)$ at $T=318.2 \mathrm{~K}$. In the present research, the impact of PEGs molar mass/polymerization on ECT solubility was not investigated because only PEG-400 was investigated in this research. In addition, PEG-400 is the most commonly used solubilizer among other grades of PEGs [16,21,22]. Nevertheless, the mole fraction solubility of drugs is known to be increased with increase in the molar mass of the solvents/co-solutes. Accordingly, in the present research, the mole fraction solubility of ECT would be enhanced with increase in the molar mass of PEGs [23]. Due to extensive use of PEG-400 in solubility enhancement, this grade was selected in this research [21,22]. 
Overall, the solubility of ECT was found good in many PS including PEG-400, EG, THP, PG, methanol and water.

The solubility values of solute also depend on the dielectric constant $\left(K_{d}\right)$ of PS. Hence, the influence of $K_{d}$ on ECT solubility at $T=298.2 \mathrm{~K}$ was also studied in this work. The $K_{d}$ values of different PS have been found in literature [24-26]. The $K_{d}$ value of ECT is not reported in literature. However, it has been reported as freely soluble in water [2]. The literature $\mathrm{K}_{\mathrm{d}}$ values for different PS at $\mathrm{T}=298.2 \mathrm{~K}$ are summarized in Table 2. Among methanol, ethanol and IPA, the solubility of ECT was found to be maximum in methanol which might be due to medium $K_{d}$ value of methanol compared to ethanol and IPA. The solubility of ECT was observed in similar magnitude in 1-butanol and 2-butanol which might be due to slightly difference in their $\mathrm{K}_{\mathrm{d}}$ values. Between EG and PG, the solubility of ECT was slightly higher in EG which might be due to higher $K_{d}$ value of EG compared to PG.

Table 2. The literature values of dielectric constants $\left(K_{d}\right)$ for different PS at $T=298.2 \mathrm{~K}$.

\begin{tabular}{ccc}
\hline PS & $\mathbf{K}_{\mathbf{d}}$ & Reference \\
\hline EA & 6.00 & {$[24]$} \\
2-Butanol & 16.60 & {$[25]$} \\
DMSO & 47.00 & {$[24]$} \\
1-Butanol & 17.64 & {$[25]$} \\
Ethanol & 25.00 & {$[24]$} \\
IPA & 17.90 & {$[24]$} \\
Water & 79.00 & {$[24]$} \\
Methanol & 33.10 & {$[26]$} \\
PG & 32.00 & {$[24]$} \\
THP & 12.60 & {$[24]$} \\
EG & 37.00 & {$[24]$} \\
PEG-400 & 14.10 & {$[24]$} \\
\hline
\end{tabular}

The $K_{d}$ value of EA is the lowest compared to other PS but ECT solubility was also recorded lowest in EA, which might be due to the fact that ECT is not a nonpolar drug. Although, the $K_{d}$ value of water was highest among other PS studied, ECT solubility was not recorded as highest or lowest in water. This observation suggested that the solubility of solutes not depend only on polarity / dielectric constant but also on molar mass, H-bonding and inter and intramolecular interactions between the solute and solvents. According to Equation (1) mentioned in the experimental section, the mole fraction solubility of solute is directly proportional to the molar mass of the PS. Hence, the maximum solubility of ECT in mole fraction in PEG-400 was possible due to its higher molar mass and lower dielectric constant compared to other PS studied.

\subsection{Estimation of Solubility Parameters Using Computational Approaches}

The values of various Hansen solubility parameters (HSPs) of ECT and different PS were obtained by applying Equation (2) and results are presented in Table 3.

The HSPs were obtained by the HSPiP software. The value of total HSP $(\delta)$ for ECT was predicted as $25.90 \mathrm{MPa}^{1 / 2}$, showing that ECT had medium polarity that means it had both hydrophilic as well as lipophilic properties. Generally, the $x_{\mathrm{e}}$ values of ECT were found higher in PS with lower or medium HSP namely PEG-400, EG, THP, PG and methanol (Table 3$)$. The polar HSP $\left(\delta_{\mathrm{p}}\right)$ of solutes, their dipole moment $(\mu)$ and molecular volume are associated with polarity. The values of molecular volume and $\mu$ of the aqueous solution of ECT have been found as $2.30 \AA^{3}$ and $9.10 \mathrm{D}$, respectively in literature [27]. The $\delta_{\mathrm{p}}$ value for ECT was found to be $12.90 \mathrm{MPa}^{1 / 2}$ in this research. Overall, the literature values of molecular volume, $\mu$ and predicted value of ECT in this research indicated that ECT had medium polarity.

Table 3. Various solubility parameters of ECT and various $P S$ at $T=298.2 \mathrm{~K}$.

\begin{tabular}{|c|c|c|c|c|c|c|c|}
\hline \multirow{2}{*}{ Components } & \multicolumn{4}{|c|}{ Hansen Solubility Parameters } & \multirow{2}{*}{$R_{\mathrm{a}}{ }^{*} / \mathrm{MPa}^{1 / 2}$} & \multirow{2}{*}{$\Delta \bar{\delta} / \mathbf{M P a}^{1 / 2}$} & \multirow{2}{*}{$\Delta \delta^{*} / \mathrm{MPa}^{1 / 2}$} \\
\hline & $\delta_{\mathrm{d}} / \mathrm{MPa}^{1 / 2}$ & $\delta_{\mathrm{p}} / \mathrm{MPa}^{1 / 2}$ & $\delta_{\mathrm{h}} / \mathrm{MPa}^{1 / 2}$ & $\delta / \mathrm{MPa}^{1 / 2}$ & & & \\
\hline ECT & 18.20 & 12.90 & 13.00 & 25.90 & - & - & - \\
\hline Water & 15.50 & 16.00 & 42.30 & 47.80 & 29.95 & 29.58 & 21.90 \\
\hline
\end{tabular}


The value of the Van Krevelen and Hoftyzer solubility parameter $(\Delta \bar{\delta})$ was obtained using Equation (3). The value of $\Delta \bar{\delta}<5.0$ was suggested for higher solubility of solute with solvent $[28,29]$. Many PS including DMSO $\left(\Delta \bar{\delta}=5.90 \mathrm{MPa}^{1 / 2}\right)$, THP $\left(\Delta \bar{\delta}=6.10 \mathrm{MPa}^{1 / 2}\right)$, ethanol $\left(\Delta \bar{\delta}=6.73 \mathrm{MPa}^{1 / 2}\right)$, IPA $\left(\Delta \bar{\delta}=7.32 \mathrm{MPa}^{1 / 2}\right)$, 1-butanol $\left(\Delta \bar{\delta}=7.32 \mathrm{MPa}^{1 / 2}\right)$, PEG-400 $\left(\Delta \bar{\delta}=7.42 \mathrm{MPa}^{1 / 2}\right)$ and 2-butanol $\left(\Delta \bar{\delta}=7.89 \mathrm{MPa}^{1 / 2}\right)$ were found to very close with the range of $\Delta \bar{\delta}<5.0 \mathrm{MPa}^{1 / 2}$, suggesting ECT had good solubility in these solvents according to this concept. The value of three-dimensional (3D) solubility parameter space $\left(R_{\mathrm{a}}\right)$ was calculated using Equation (4). The value of $R_{\mathrm{a}}<5.6$ has been recommended for higher solubility of solute with solvent $[20,30]$. Some PS including DMSO $\left(R_{\mathrm{a}}=6.06 \mathrm{MPa}^{1 / 2}\right)$, THP $\left(R_{\mathrm{a}}=6.93 \mathrm{MPa}^{1 / 2}\right)$, ethanol $\left(R_{\mathrm{a}}=7.57 \mathrm{MPa}^{1 / 2}\right)$, 1-butanol $\left(R_{\mathrm{a}}=8.34 \mathrm{MPa}^{1 / 2}\right)$, IPA $\left(R_{\mathrm{a}}=8.42 \mathrm{MPa}^{1 / 2}\right)$ and 2-butanol $\left(R_{\mathrm{a}}=8.92 \mathrm{MPa}^{1 / 2}\right)$ were found to very close with the range of $R_{\mathrm{a}}<5.6 \mathrm{MPa}^{1 / 2}$, suggesting ECT had good solubility in these solvents according to this concept. Another solubility parameter, the Greenhalgh's solubility parameter $(\Delta \delta)$ was obtained using Equation (5). The value of $\Delta \delta<7.0 \mathrm{MPa}^{1 / 2}$ has been recommended for higher solubility of solute with solvent [31]. Most of the PS such as ethanol $\left(\Delta \delta=0.50 \mathrm{MPa}^{1 / 2}\right)$, DMSO $\left(\Delta \delta=2.30 \mathrm{MPa}^{1 / 2}\right)$, 1-butanol $\left(\Delta \delta=3.00 \mathrm{MPa}^{1 / 2}\right)$, 2butanol $\left(\Delta \delta=3.10 \mathrm{MPa}^{1 / 2}\right)$, PG $\left(\Delta \delta=3.30 \mathrm{MPa}^{1 / 2}\right)$, IPA $\left(\Delta \delta=3.60 \mathrm{MPa}^{1 / 2}\right)$, methanol $\left(\Delta \delta=4.40 \mathrm{MPa}^{1 / 2}\right)$, THP $\left(\Delta \delta=4.50 \mathrm{MPa}^{1 / 2}\right)$, EG $\left(\Delta \delta=5.70 \mathrm{MPa}^{1 / 2}\right), \quad$ PEG-400 $\left(\Delta \delta=7.00 \mathrm{MPa}^{1 / 2}\right)$ and $\mathrm{EA}\left(\Delta \delta=7.80 \mathrm{MPa}^{1 / 2}\right)$ were found to very close with the range of $\Delta \delta<7.0 \mathrm{MPa}^{1 / 2}$, suggesting ECT had good solubility in these solvents according to this concept. Overall, different solubility trend of ECT was observed based on various solubility parameter approaches. The highest solubility of ECT was recorded in PEG-400 and lowest solubility was observed in EA. Although, the different HSPs of PEG-400 and EA were not found lowest and highest, there is a certain relationship between the solubility and HSPs. The solubility of drugs depends not only on HSPs parameters but also depends on other parameters namely molar mass of the solute and solvent, intermolecular interactions between the solute and solvents and intramolecular interactions between the solute and solute and solvents and solvents, etc. [20]. The highest solubility of ECT in PEG-400 could be possible due to higher molar mass, higher H-bonding interactions between ECT and PEG-400 and lower dielectric constant. Overall, PEG-400 was found as the best solvent for solubility/miscibility of ECT.

\subsection{Ideal Solubilities and Activity Coefficients}

The "activity coefficients $\left(\gamma_{i}\right)$ " were estimated to study the molecular interactions between ECT and respective PS. The "ideal solubility $\left(x^{\mathrm{idl}}\right)^{\prime \prime}$ values for ECT were obtained by applying Equation (6) and results are presented in Table 1 . The $x^{\text {idl }}$ values of ECT were calculated as $3.74 \times 10^{-2}$ to $6.76 \times 10^{-2}$ at $T=298.2 \mathrm{~K}$ to $318.2 \mathrm{~K}$. The $x^{\text {idl }}$ values of ECT were found very closed with $x_{\mathrm{e}}$ values of ECT in EG at each temperature studied $(p>0.05)$. However, the $x^{\mathrm{idl}}$ values of ECT were found significantly lower than $x_{\mathrm{e}}$ values of ECT in PEG-400 ( $p$ 0.05). On the other hand, the $x^{\text {idl }}$ values of ECT were observed slightly higher than $x_{\mathrm{e}}$ values of ECT in THP, PG and methanol. While, the $x^{\mathrm{idl}}$ values of ECT were found significantly higher than $x_{\mathrm{e}}$ values of ECT in EA, 1-butanol, 2-butanol, DMSO, ethanol, IPA and water $(p<0.05)$. Based on these results, PEG-400 was chosen as the ideal solvent for solubility/miscibility of ECT.

The values of $\gamma_{i}$ for ECT in twelve different PS at $T=298.2 \mathrm{~K}$ to $318.2 \mathrm{~K}$ were calculated by applying Equation (8) and results are presented in Table 4. 
Table 4. Activity coefficients $\left(\gamma_{\mathrm{i}}\right)$ of ECT in various $P S$ at $T=298.2 \mathrm{~K}$ to $318.2 \mathrm{~K}$.

\begin{tabular}{|c|c|c|c|c|c|}
\hline \multirow{2}{*}{$P S$} & \multicolumn{5}{|c|}{$\gamma_{i}$} \\
\hline & $T=298.2 \mathrm{~K}$ & $T=303.2 \mathrm{~K}$ & $T=308.2 \mathrm{~K}$ & $T=313.2 \mathrm{~K}$ & $T=318.2 \mathrm{~K}$ \\
\hline EA & 103.18 & 81.56 & 71.00 & 58.73 & 52.78 \\
\hline 2-Butanol & 15.40 & 14.58 & 12.83 & 11.54 & 10.32 \\
\hline DMSO & 14.58 & 13.83 & 12.36 & 10.95 & 10.25 \\
\hline 1-Butanol & 12.95 & 12.57 & 11.68 & 10.90 & 9.87 \\
\hline Ethanol & 9.80 & 9.59 & 9.50 & 9.30 & 8.71 \\
\hline IPA & 9.46 & 9.38 & 9.05 & 8.66 & 8.25 \\
\hline Water & 4.66 & 5.02 & 5.34 & 5.64 & 5.94 \\
\hline Methanol & 3.44 & 3.69 & 3.99 & 4.24 & 4.52 \\
\hline PG & 1.20 & 1.33 & 1.45 & 1.59 & 1.73 \\
\hline THP & 1.16 & 1.26 & 1.32 & 1.39 & 1.45 \\
\hline EG & 0.80 & 0.89 & 0.98 & 1.08 & 1.18 \\
\hline PEG-400 & 0.34 & 0.37 & 0.40 & 0.44 & 0.47 \\
\hline
\end{tabular}

The values of $\gamma_{\mathrm{i}}$ for ECT were calculated $<1.0$ in PS such as PEG-400 and EG at each temperature studied. The values of $\gamma_{\mathrm{i}}$ for ECT were found much closed to $1.0 \mathrm{in}$ PG and THP at each temperature level. While, the $\gamma_{i}$ value for ECT was observed significantly higher in EA. The influence of $K_{d}$ on $\gamma_{i}$ values of ECT was also evaluated. The $K_{d}$ values of various PS at $T=298.2 \mathrm{~K}$ are included in Table 2. Among methanol, ethanol and IPA, the $\gamma_{i}$ value of ECT was found to be lowest in methanol. The $\gamma_{i}$ value of ECT was observed slightly lower in 1-butanol compared to 2-butanol which was possible due to slightly difference in their $K_{d}$ values. Between EG and PG, the $\gamma_{i}$ value of ECT was slightly lower in EG which might be due to higher $K_{d}$ value of EG compared to PG. Overall, the results of activity coefficients were found in same trend of solubility data and dielectric constants. Based on the data of activity coefficients, the highest molecular interactions were seen in ECT-PEG-400, ECT-EG, ECT-THP and ECT-PG in comparison with other combination of ECT and PS.

\subsection{Computational Approaches for Solubility Correlation}

The $x_{\mathrm{e}}$ values of ECT recorded in this work were correlated with three different computational models such as the Apelblat, van't Hoff and Buchowski-Ksiazaczak $\lambda h$ models [20,32-35]. The $x_{\mathrm{e}}$ and Apelblat solubility $\left(x^{\mathrm{Apl}}\right)$ values of ECT were calculated using Equations (1) and (9), respectively. The graphical correlation of $\ln x_{\mathrm{e}}$ values of ECT with its $\ln x^{\mathrm{Apl}}$ values in twelve different PS as a function of $1 / T$ is shown in Figure 4 . The data summarized in Figure 4 suggested good correlation of $\ln x_{\mathrm{e}}$ values of ECT with its $\ln$ $x^{\mathrm{Apl}}$ values in all twelve different PS. 


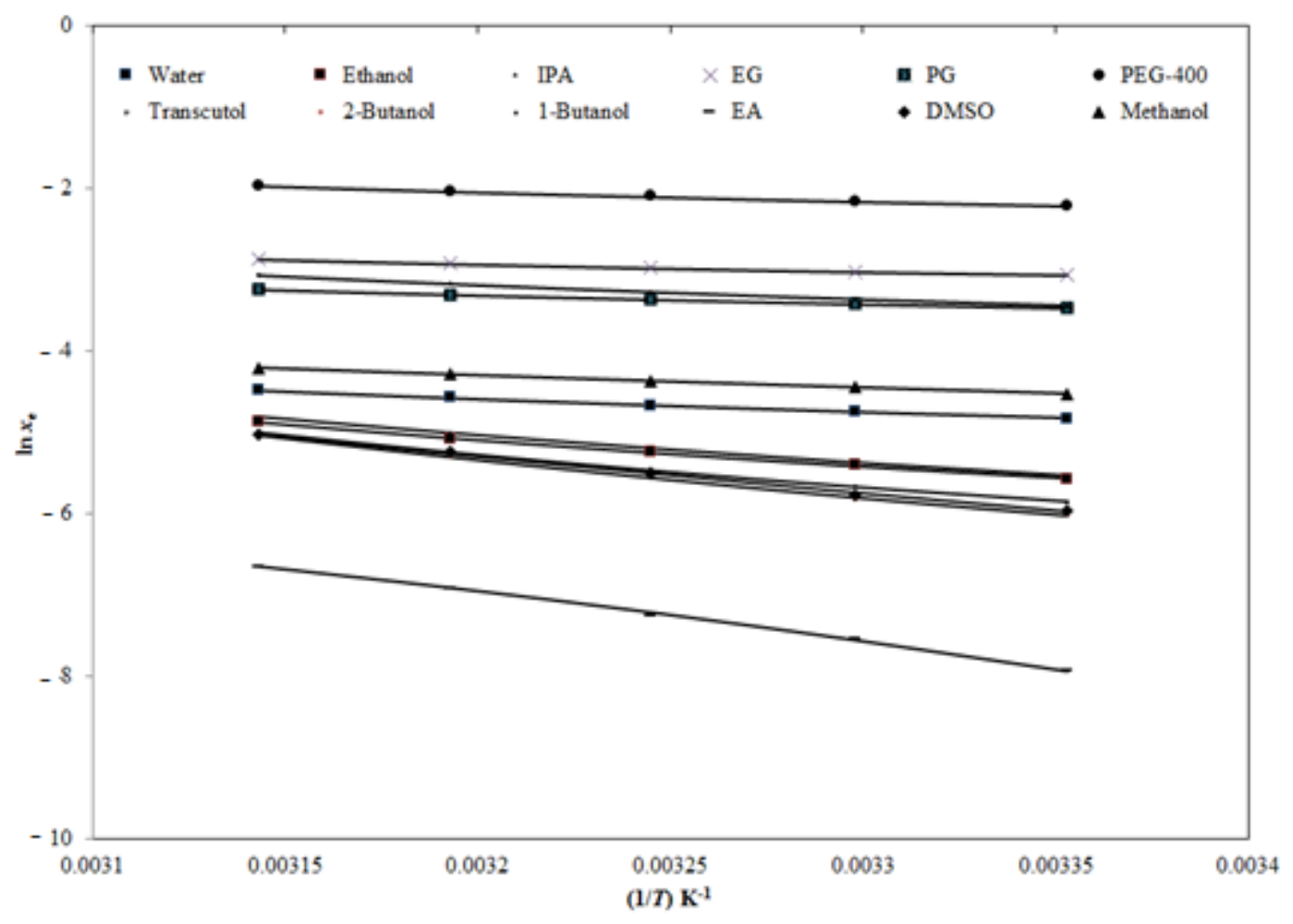

Figure 4. Correlation of experimental natural logarithmic solubilities $\left(\ln x_{\mathrm{e}}\right)$ of ECT with the Apelblat model in various pure solvents as a function of $1 / T$; symbols represent the experimental $\ln x_{\mathrm{e}}$ values of ECT and the solid lines represent the $\ln$ $x^{\mathrm{Apl}}$ values calculated by the Apelblat model.

The Apelblat correlation results are listed in Table 5.

Table 5. Results of the Apelblat model in terms of the Apelblat parameters $(A, B$ and $C), R^{2}$ and root mean square deviation (RMSD) for ECT in various $P S^{\mathrm{b}}$.

\begin{tabular}{ccccccc}
\hline $\boldsymbol{P S}$ & $\boldsymbol{A}$ & $\boldsymbol{B}$ & $\boldsymbol{C}$ & $\boldsymbol{R}^{\mathbf{2}}$ & $\boldsymbol{R M S D}$ (\%) & $\begin{array}{c}\text { Overall } \\
\boldsymbol{R} M S D(\%)\end{array}$ \\
\hline EA & 756.93 & $-40,177.60$ & -110.59 & 0.9993 & 1.96 & \\
2-Butanol & -565.49 & $21,632.90$ & 85.45 & 0.9991 & 1.42 & \\
DMSO & -269.00 & 8184.21 & 41.34 & 0.9977 & 1.62 & \\
1-Butanol & -704.53 & $28,585.44$ & 105.80 & 0.9999 & 1.16 & \\
Ethanol & -509.45 & $20,319.03$ & 76.47 & 0.9989 & 1.15 & \\
IPA & -464.21 & $18,103.22$ & 69.84 & 0.9998 & 0.66 & 0.87 \\
Water & -232.41 & 9030.47 & 34.62 & 0.9998 & 0.46 & \\
Methanol & -95.77 & 2908.17 & 14.30 & 0.9994 & 0.24 & \\
PG & -136.47 & 5194.27 & 20.28 & 0.9997 & 0.21 & \\
THP & -303.07 & $12,231.01$ & 45.38 & 0.9995 & 0.62 & \\
EG & -193.44 & 7911.56 & 28.75 & 0.9999 & 0.51 & \\
PEG-400 & -191.99 & 7671.17 & 28.79 & 0.9998 & 0.54 & \\
\hline
\end{tabular}

b The relative uncertainties $u_{\mathrm{r}}$ are $u_{\mathrm{r}}(A)=0.60, u_{\mathrm{r}}(B)=0.72$ and $u_{\mathrm{r}}(C)=0.60$.

Different Apelblat model parameters like $A, B$ and $C$ were determined from experimental solubility data of ECT. The values of $x^{\mathrm{Apl}}$ for ECT were back calculated using model parameters. The correlation between $x_{\mathrm{e}}$ and $x^{\mathrm{Apl}}$ values of ECT was performed using root mean square deviation $(R M S D)$ and determination coefficient $\left(R^{2}\right)$ values. The $R M S D$ value was calculated using Equation (10). The RMSD values for ECT in twelve different PS were obtained as $(0.21$ to 1.96$) \%$. The overall $R M S D$ value was calculated as $0.87 \%$. The regressed $R^{2}$ values for ECT in twelve different PS were calculated as 0.9977 to 0.9999 . The 
lower values of RMSD and higher $R^{2}$ values showed good correlation of $x_{\mathrm{e}}$ values of ECT with the Apelblat model.

The van't Hoff solubility $\left(x^{\text {van't }}\right)$ values of ECT were calculated using Equation (11). The van't Hoff model parameters ( $a$ and $b$ ) were calculated from experimental solubility values of ECT. The $x^{\text {van't }}$ values of ECT were back calculated using model parameters. The graphical correlation of $\ln x_{\mathrm{e}}$ values of ECT with its $\ln x^{\mathrm{van} t \mathrm{t}}$ values in twelve different PS as a function of $1 / T$ is given in supplementary Figure S1 (Figure S1). The data summarized in Figure $\mathrm{S} 1$ also showed good correlation of $\ln x_{\mathrm{e}}$ values of ECT with its $\ln x^{\text {van't }}$ values. The results of van't Hoff correlation are listed in Table 6. The RMSD values for ECT in twelve different PS were obtained as (0.67 to 2.39$) \%$. The overall RMSD was calculated as $1.42 \%$. The $R^{2}$ values for ECT in twelve different PS were estimated as 0.9942 to 0.9987 . The lower $R M S D$ values and higher $R^{2}$ values again suggested good correlation of $x_{\mathrm{e}}$ values of ECT with "van't Hoff model".

Table 6. Results of van't Hoff model in terms of model parameters ( $a$ and $b$ ), $R^{2}$ and $R M S D$ for ECT in various $P S{ }^{\mathrm{c}}$.

\begin{tabular}{cccccc}
\hline $\boldsymbol{P S}$ & $\boldsymbol{a}$ & $\boldsymbol{b}$ & $\boldsymbol{R}^{\mathbf{2}}$ & $\boldsymbol{R} M S D(\%)$ & Overall $\mathbf{R M S D}$ (\%) \\
\hline EA & 12.14 & -5976.00 & 0.9972 & 2.39 & \\
2-Butanol & 9.92 & -4762.30 & 0.9970 & 1.98 & \\
DMSO & 9.36 & -4578.30 & 0.9971 & 1.97 & \\
1-Butanol & 7.87 & -4099.30 & 0.9955 & 2.08 & \\
Ethanol & 5.50 & -3305.90 & 0.9953 & 1.81 & \\
IPA & 6.09 & -3471.60 & 0.9971 & 1.40 & \\
Water & 0.75 & -1665.80 & 0.9969 & 0.71 & \\
Methanol & 0.52 & -1507.20 & 0.9987 & 0.98 & \\
PG & 0.11 & -1071.50 & 0.9974 & 1.06 & \\
THP & 2.55 & -1790.60 & 0.9952 & 0.93 & \\
EG & 0.18 & -972.49 & 0.9942 & 1.07 & \\
PEG-400 & 1.88 & -1223.40 & 0.9962 & 0.67 & \\
\hline C The relative uncertainties $u_{\mathrm{r}}$ are $u_{\mathrm{r}}(a)=0.90$ and $u_{\mathrm{r}}(b)=0.59$ & &
\end{tabular}

The Buchowski-Ksiazaczak $\lambda h$ model solubility $(\mathrm{x})$ values of ECT were predicted using Equation (12) and results are summarized in Table 7. The RMSD values for ECT in twelve different PS were predicted as (0.79 to 2.84$) \%$. The overall RMSD was predicted as $1.65 \%$. The lower $R M S D$ values again indicated good correlation of $x_{\mathrm{e}}$ values of ECT with Buchowski-Ksiazaczak $\lambda h$ model. Overall, the performance of each studied theoretical model was excellent for the correlation of experimental solubility data of ECT based on recorded $R M S D$ values. However, the Apelblat model was found to be the best theoretical model for solubility correlation due to lowest $R M S D$ value.

Table 7. Results of the Buchowski-Ksiazaczak $\lambda h$ model in terms of model parameters $(\lambda$ and $h)$ and $R M S D$ for ECT in various $P S^{\mathrm{d}}$.

\begin{tabular}{ccccc}
\hline $\boldsymbol{P S}$ & $\boldsymbol{\lambda}$ & $\boldsymbol{h}$ & RMSD (\%) & Overall $R$ MSD (\%) \\
\hline EA & 0.82 & 7255.94 & 2.84 & \\
2-Butanol & 0.20 & 22884.67 & 2.65 & \\
DMSO & 0.33 & 13682.90 & 2.24 & \\
1-Butanol & 0.70 & 5794.06 & 1.95 & \\
Ethanol & 1.22 & 2708.86 & 1.86 & \\
IPA & 1.02 & 3392.22 & 1.70 & \\
Water & 2.14 & 777.68 & 1.58 & \\
Methanol & 1.99 & 755.86 & 1.28 & \\
PG & 1.38 & 773.75 & 1.15 & \\
THP & 0.63 & 2823.84 & 0.98 & \\
EG & 1.08 & 897.04 & 0.86 & \\
PEG-400 & 0.02 & 50767.60 & 0.79 & \\
\hline
\end{tabular}

d The relative uncertainties $u_{\mathrm{r}}$ are $u_{\mathrm{r}}(\lambda)=0.68$ and $u_{\mathrm{r}}(\mathrm{h})=1.55$. 


\subsection{Thermodynamic Analysis}

The obtained values of various apparent thermodynamic parameters of ECT along with $R^{2}$ values are listed in Table 8. The values of apparent standard enthalpy $\left(\Delta_{\text {sol }} H^{0}\right)$ for ECT were calculated by applying Equation (13). The " $\Delta_{\text {sol }} H^{0}$ values" for ECT dissolution in twelve different PS were calculated as (8.09 to 49.75$) \mathrm{kJ} \mathrm{mol}^{-1}$. Generally, the $\Delta_{\text {sol }} H^{0}$ values of ECT were found maximum in PS with lower solubilities of ECT such as EA, DMSO, 1butanol and 2-butanol etc. However, the $\Delta_{\mathrm{sol}} H^{0}$ values of ECT were found minimum in PS with higher solubilities of ECT such as PEG-400, EG, THP and PG. The values of apparent standard Gibbs free energy $\left(\Delta_{\mathrm{sol}} G^{0}\right)$ for ECT were calculated by applying Equation (14). The " $\Delta_{\text {sol }} G^{0}$ values" for ECT dissolution were calculated as (5.34 to 18.57$) \mathrm{kJ} \mathrm{mol}^{-1}$.

Table 8. Apparent thermodynamic parameters $\left(\Delta_{\mathrm{sol}} H^{0}, \Delta_{\mathrm{sol}} G^{0}\right.$ and $\left.\Delta_{\mathrm{sol}} S^{0}\right)$ along with $R^{2}$ values for ECT in various $P S$ e.

\begin{tabular}{|c|c|c|c|c|}
\hline$P S$ & $\Delta_{\mathrm{sol}} H^{0} / \mathrm{kJ} \mathrm{mol}^{-1}$ & $\Delta_{\mathrm{sol}} G^{0} / \mathrm{kJ} \mathrm{\textrm {mol } ^ { - 1 }}$ & $\Delta_{\mathrm{sol}} S^{0} / \mathrm{J} \mathrm{mol}{ }^{-1} \mathrm{~K}^{-1}$ & $R^{2}$ \\
\hline EA & 49.75 & 18.57 & 101.20 & 0.9971 \\
\hline 2-Butanol & 39.65 & 14.17 & 82.70 & 0.9971 \\
\hline DMSO & 38.11 & 14.07 & 78.06 & 0.9972 \\
\hline 1-Butanol & 34.13 & 13.91 & 65.64 & 0.9957 \\
\hline Ethanol & 27.52 & 13.37 & 45.92 & 0.9954 \\
\hline IPA & 28.90 & 13.25 & 50.78 & 0.9972 \\
\hline Water & 13.86 & 11.92 & 6.32 & 0.9970 \\
\hline Methanol & 12.54 & 11.17 & 4.45 & 0.9988 \\
\hline PG & 8.92 & 8.60 & 1.03 & 0.9975 \\
\hline THP & 14.90 & 8.35 & 21.28 & 0.9954 \\
\hline EG & 8.09 & 7.60 & 1.61 & 0.9944 \\
\hline PEG-400 & 10.18 & 5.34 & 15.71 & 0.9963 \\
\hline
\end{tabular}

e The relative uncertainties are $u\left(\Delta_{\text {sol }} H^{0}\right)=0.59, u\left(\Delta_{\text {sol }} G^{0}\right)=0.31$ and $u\left(\Delta_{\text {sol }} S^{0}\right)=0.90$.

The $\Delta_{\text {sol }} G^{0}$ value of ECT was found minimum in PEG-400 $\left(5.34 \mathrm{~kJ} \mathrm{~mol}^{-1}\right)$ which was possible due to the highest solubility of ECT in PEG-400. The $\Delta_{\text {sol }} G^{0}$ value of ECT was found maximum in EA $\left(18.57 \mathrm{~kJ} \mathrm{~mol}^{-1}\right)$ which was possible due to the lowest solubility of ECT in EA. The results of $\Delta_{\text {sol }} G^{0}$ value of ECT were found in accordance with solubility trend of ECT in twelve different PS. The recorded data of $\Delta_{\text {sol }} H^{0}$ and $\Delta_{\text {sol }} G^{0}$ for ECT in twelve different PS suggested an endothermic dissolution of ECT in all these PS [36,37]. The values of apparent standard entropy $\left(\Delta_{\mathrm{sol}} S^{0}\right)$ for ECT were estimated using Equation (15). The $\Delta_{\mathrm{sol}} S^{0}$ values for ECT dissolution were calculated as (1.03 to 101.20$) \mathrm{J} \mathrm{mol}^{-1} \mathrm{~K}^{-1}$, suggesting an entropy-driven dissolution of ECT in all PS studied [37]. The mean relative uncertainties in $\Delta_{\text {sol }} H^{0}, \Delta_{\text {sol }} G^{0}$ and $\Delta_{\text {sol }} S^{0}$ for ECT dissolution were calculated as 0.59, 0.31 and 0.90, respectively. Overall, the dissolution of ECT has been considered as an endothermic and entropy-driven in all twelve PS investigated [36,37].

\section{Materials and Methods}

\subsection{Materials}

ECT, methanol, ethanol, IPA, 1-butanol and 2-butanol were obtained from Sigma Aldrich (St. Louis, MO, USA). THP was donated as a kind gift sample from Gattefosse (Lyon, France). EG, PG, PEG-400, EA and DMSO were obtained from Fluka Chemica (Busch, Switzerland). Water was collected from a Milli-Q unit. All the materials (including ECT) provided by the supplier were of high purity and used without any further purification. The information and properties of materials are listed in Table S1.

\subsection{Analysis of ECT}

The analysis of ECT in all in vitro samples was conducted using a reversed phase high performance liquid chromatography (HPLC) system connected with an ultraviolet (UV) detector at $\lambda_{\max }=254 \mathrm{~nm}$. The chromatographic quantification of ECT was carried out at $T=298.2 \mathrm{~K}$ using a Waters HPLC system (Waters, Milford, MA, USA). A Nucleodur 
$(150 \times 4.6 \mathrm{~mm}, 5 \mu \mathrm{m}) \mathrm{RP} \mathrm{C}_{18}$ column was used for reversed phase HPLC analysis of ECT. The binary mixture of ethanol and methanol (50:50\%) was utilized as the mobile phase. The mobile phase was flowed with a flow rate of $1.0 \mathrm{~mL} \mathrm{~min}^{-1}$ at $254 \mathrm{~nm}$ for the elution of ECT. The volume of injection volume and retention time was $20 \mu \mathrm{L}$ and $1.6 \mathrm{~min}$, respectively. The calibration curve (CC) of ECT was obtained by plotting the concentrations of ECT against recorded HPLC area. The CC of ECT was found linear in the range of $(0.1-100) \mu \mathrm{g} \mathrm{g}^{-1}$ with $R^{2}$ value of 0.9992 . The regression equation for ECT was recorded as $y=18,911 x+12,028$; in which $x$ and y represent the concentration of ECT and measured HPLC area, respectively. This regression equation was applied for the estimation of ECT concentration in unknown solubility samples.

\subsection{Solid Phase Characterization of ECT}

The solid phase characterization of ECT in its pure form and equilibrated sample was performed by DSC. The thermal parameters, crystallinity and any transformation of ECT were evaluated using DSC technique. Equilibrated ECT was obtained from equilibrated sample of ethanol containing ECT by its slow evaporation $[17,18]$. DSC investigation of pure and equilibrated ECT was performed using a DSC-8000 instrument (Perkin Elmer, Akron, OH, USA). The whole assembly was equipped a with chiller $(T=253.2 \mathrm{~K})$ and autosampler. For DSC analysis, accurately weighed $4.50 \mathrm{mg}$ of pure and equilibrated ECT were taken into aluminum pan which were sealed hermetically. The flow rate of nitrogen was set at $20 \mathrm{~mL} \mathrm{~min}^{-1}$ for the analysis of both samples. The samples were heated with $10 \mathrm{~K} \mathrm{~min}^{-1}$ heating rate in the range of $T=303.2$ to $523.2 \mathrm{~K}$ for both samples.

\subsection{Solubility Measurement of ECT}

The solubilities of ECT in twelve different PS were measured using an experimental approach by applying a saturation shake flask technique at $T=298.2 \mathrm{~K}$ to $318.2 \mathrm{~K}$ and $p=0.1 \mathrm{MPa}[38,39]$. The operation and experimental procedure of this study were same as reported in previously published studies $[17,20]$. Hence, the experimental conditions are not described here. Each experiment was carried out in triplicates manner $(n=3.0)$ in order to establish good statistical analysis. The concentration of ECT in experimental saturated samples of each PS was estimated by HPLC technique at $\lambda_{\max }=254 \mathrm{~nm}$. The amount of ECT $\left(\mu \mathrm{g} \mathrm{g}^{-1}\right.$ ) was obtained from the CC of ECT discussed under Section 3.2. Finally, the $x_{\mathrm{e}}$ values of ECT were obtained using the following equation $[19,20]$ :

$$
x_{\mathrm{e}}=\frac{m_{1} / M_{1}}{m_{1} / M_{1}+m_{2} / M_{2}}
$$

Here, $m_{1}=$ mass of ECT; $m_{2}=$ mass of PS; $M_{1}=$ molar mass of ECT and $M_{2}=$ molar mass of PS.

\subsection{Estimation of Solubility Parameters Using Computational Approaches}

The solute at a standard condition of temperature and pressure reaches highest solubility/miscibility in PS having the similar solubility parameter [40]. Hence, different solubility parameters for ECT and twelve different PS were calculated in this work. The value of total HSP was calculated by applying following equation $[20,40,41]$ :

$$
\delta^{2}=\delta_{\mathrm{d}}^{2}+\delta_{\mathrm{p}}^{2}+\delta_{\mathrm{h}}^{2}
$$

Here, $\delta=$ total HSP; $\delta_{\mathrm{d}}=$ dispersion HSP; $\delta_{\mathrm{p}}=$ polar HSP and $\delta_{\mathrm{h}}=$ hydrogen-bonded HSP. The values of different HSPs for ECT and twelve different PS were estimated using HSPiP software (version 4.1.07, Louisville, KY, USA).

However, the $\Delta \bar{\delta}$ value was calculated by applying the following equation [28]:

$$
\Delta \bar{\delta}=\left[\left(\delta_{\mathrm{d} 2}^{2}-\delta_{\mathrm{d} 1}^{2}\right)+\left(\delta_{\mathrm{p} 2}^{2}-\delta_{\mathrm{p} 1}^{2}\right)+\left(\delta_{\mathrm{h} 2}^{2}-\delta_{\mathrm{h} 1}^{2}\right)\right]^{1 / 2}
$$


It has been reported that if $\Delta \bar{\delta}<5.0 \mathrm{MPa}^{1 / 2}$, the possibility of miscibility between solute and solvent is maximum $[28,29]$.

The value of $R_{\mathrm{a}}$ was obtained by applying the following equation [30,42]:

$$
\mathrm{Ra}^{2}=4\left(\delta_{\mathrm{d} 2}-\delta_{\mathrm{d} 1}\right)^{2}+\left(\delta_{\mathrm{p} 2}-\delta_{\mathrm{p} 1}\right)^{2}+\left(\delta_{\mathrm{h} 2}-\delta_{\mathrm{h} 1}\right)^{2}
$$

Here, subscript 1 and 2 refer to the respective PS and ECT, respectively. For maximum miscibility between the solute and PS, the $R_{\mathrm{a}}$ value should be $<5.6 \mathrm{MPa}^{1 / 2}$ [30].

The $\Delta \delta$ value was obtained by applying the following equation [31]:

$$
\Delta \delta=\delta_{2}-\delta_{1}
$$

It was suggested that the miscibility between solute and PS is higher at $\Delta \delta<7.0 \mathrm{MPa}^{1 / 2}$. While, the value of $\Delta \delta>10.0 \mathrm{MPa}^{1 / 2}$ is suggested for insolubility between the solute and solvent [20,31].

\subsection{Ideal Solubilities and Activity Coefficients}

The $x^{\text {idl }}$ value of ECT was calculated by applying the following equation [43]:

$$
\ln x^{\mathrm{idl}}=\frac{-\Delta H_{\text {fus }}\left(T_{\text {fus }}-T\right)}{R T_{\text {fus }} T}+\left(\frac{\Delta C_{\mathrm{p}}}{R}\right)\left[\frac{T_{\text {fus }}-T}{T}+\ln \left(\frac{T}{T_{\text {fus }}}\right)\right]
$$

Here, $R=$ universal gas constant and other parameters have already been explained in previous text. The $\Delta C_{p}$ for ECT was calculated by applying the following equation [43,44]:

$$
\Delta C_{\mathrm{p}}=\frac{\Delta H_{\text {fus }}}{T_{\text {fus }}}
$$

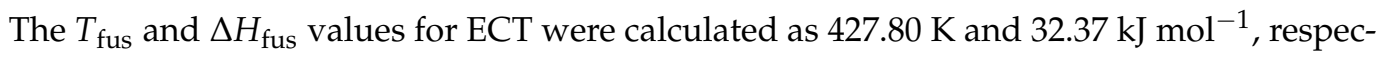
tively using thermal (i.e., DSC) analysis. Using Equation (7), the $\Delta C_{\mathrm{p}}$ of ECT was obtained as $75.66 \mathrm{~J} \mathrm{~mol}^{-1} \mathrm{~K}^{-1}$. The $x^{\text {idl }}$ values for ECT were now obtained by applying Equation (6).

The $\gamma_{\mathrm{i}}$ values for ECT in twelve different PS were estimated by applying the following equation $[43,45]$ :

$$
\gamma_{\mathrm{i}}=\frac{x^{\mathrm{idl}}}{x_{\mathrm{e}}}
$$

The $\gamma_{\mathrm{i}}$ data for the solute in various PS are used for the description of drug-solvent interactions at molecular level. If the values of $\gamma_{i}$ are lower, the drug-solvent interactions at molecular level will be higher and vice verse.

\subsection{Solubility Validation/Correlation Using Computational Approaches}

Computational analysis of experimental solubility value of drugs is important for their practical predictions and validations $[38,46]$. Hence, the experimental solubility values of ECT in twelve different PS were correlated using three computational models namely the Apelblat, van't Hoff and Buchowski-Ksiazaczak $\lambda h$ models [20,32-35]. According to the Apelblat model, the solubility of solute depends on the temperature and it can be used to correlate the experimental solubility data of both polar as well as non-polar solutes [32]. It represents the relationship between the solubility and temperature in semi-empirical form. The $x^{\mathrm{Apl}}$ value of ECT was estimated by applying the following equation [32,33]:

$$
\ln x^{\mathrm{Apl}}=A+\frac{B}{T}+C \ln (T)
$$

Here, $A, B$ and $C=$ the parameters of the Apelblat model and the values of these parameters were estimated by applying nonlinear multivariate regression analysis of experimental solubilities of ECT listed in Table 1 [20]. These parameters reflect the influence of non-ideality of the solution on ECT mole fraction solubility. The $x_{\mathrm{e}}$ values of ECT were 
correlated with $x^{\mathrm{Apl}}$ values of ECT in terms of RMSD and $R^{2}$ values. The RMSD for ECT was obtained by applying the following equation:

$$
R M S D=\left[\frac{1}{N} \sum_{i=1}^{N}\left(\frac{x^{\mathrm{Apl}}-x_{\mathrm{e}}}{x_{\mathrm{e}}}\right)^{2}\right]^{\frac{1}{2}}
$$

Here, $N=$ the number of data points used in the experiment.

The van't Hoff model is used to describe the relationship between the solubility of solute with reciprocal of temperature and used to correlate the experimental solubility data of polar solutes. It is also a semi-empirical model. The $x^{\text {van't }}$ value of ECT was obtained by applying the following equation [20]:

$$
\ln x^{\mathrm{van}^{\prime} \mathrm{t}}=\mathrm{a}+\frac{b}{T}
$$

Here, $a$ and $b=$ the parameters of the van't Hoff model and the values of these parameters were estimated by plotting $\ln x_{\mathrm{e}}$ values of ECT against $1 / T$.

The Buchowski-Ksiazaczak $\lambda h$ model is the other model used to describe solution behavior and correlation of solubility data. This model can be used to fit the experimental data well for various systems with only two parameters i.e., $\lambda$ and $h$ [34]. The BuchowskiKsiazaczak $\lambda h$ model solubility of ECT was obtained using the following equation $[34,35]$ :

$$
\ln \left[1+\frac{\lambda(1-x)}{x}\right]=\lambda h\left[\frac{1}{T}-\frac{1}{T_{\text {fus }}}\right]
$$

Here, $\lambda$ and $h=$ the parameters of Buchowski-Ksiazaczak $\lambda h$ model and $x=$ mole fraction solubility of ECT for Buchowski-Ksiazaczak $\lambda h$ model. The parameter $\lambda$ represents the non-ideality of the solution.

\subsection{Thermodynamic Analysis}

For the calculation of thermodynamics parameters of ECT in twelve different PS, an apparent thermodynamic analysis was performed. Three thermodynamic parameters namely $\Delta_{\mathrm{sol}} H^{0}, \Delta_{\mathrm{sol}} G^{0}$ and $\Delta_{\mathrm{sol}} S^{0}$ for ECT were estimated by applying the van't Hoff and Krug et al. analysis [43,47,48]. The $\Delta_{\text {sol }} H^{0}$ values for ECT dissolution in twelve different PS were obtained at a mean harmonic temperature $\left(T_{\mathrm{hm}}\right)$ of $308 \mathrm{~K}$ using "van't Hoff analysis" by applying the following equation $[43,47]$ :

$$
\left(\frac{\partial \ln x_{\mathrm{e}}}{\partial\left(\frac{1}{T}-\frac{1}{T_{\mathrm{hm}}}\right)}\right)_{P}=-\frac{\Delta_{\mathrm{sol}} H^{0}}{R}
$$

The $\Delta_{\text {sol }} H^{0}$ values were estimated by "van't Hoff" plots made between $\ln x_{\mathrm{e}}$ values of ECT against $\frac{1}{T}-\frac{1}{T_{h m}}$. The representative van't Hoff graphs are given in Figure S2.

The $\Delta_{\text {sol }} G^{0}$ values for ECT dissolution in twelve different PS were also calculated at $T_{\mathrm{hm}}$ of $308 \mathrm{~K}$ using "Krug et al. analysis" by applying the following equation [47]:

$$
\Delta_{\mathrm{sol}} G^{0}=-R T_{\mathrm{hm}} \times \text { intercept }
$$

Here, the intercept values for ECT in twelve different PS were calculated using van't Hoff plots shown in Figure S2.

Finally, the $\Delta_{\text {sol }} S^{0}$ values for ECT dissolution were obtained by applying the following equation $[43,47,48]$ :

$$
\Delta_{\mathrm{sol}} S^{0}=\frac{\Delta_{\mathrm{sol}} H^{0}-\Delta_{\mathrm{sol}} G^{0}}{T_{\mathrm{hm}}}
$$




\subsection{Statistical Analysis}

Statistical evaluation was performed using Kruskal-Wallis analysis followed by Denn's test. The "GraphpadInstat software (San Diego, CA, USA) was used to perform all statistical tests. The $p<0.05$ was taken as significant value.

\section{Conclusions}

The solubility data, various solubility parameters and thermodynamic behavior of ECT in twelve different PS were obtained using different experimental and computational approaches. Experimental solubility values of ECT were measured using a saturation shake flask method. The solid phases of ECT in pure and equilibrated samples were characterized using DSC analysis. The results of DSC analysis showed no transformation of ECT in solvates/polymorphs/hydrates. The experimental solubilities of ECT were correlated well by the van't Hoff, Apelblat and Buchowski-Ksiazaczak $\lambda h$ models with overall RMSD values of $1.42,0.87$ and $1.65 \%$, respectively. Overall, the performance of each studied model was excellent. However, the Apelblat model was found to be the best theoretical model due to lowest RMSD value. The solubility of ECT was found to be increasing with the raise in temperature in all PS evaluated. The solubility of ECT was found maximum in PEG-400, followed by EG, THP, PG, methanol, water, IPA, ethanol, 1-butanol, DMSO, 2-butanol and EA at $T=318.2 \mathrm{~K}$. The results of activity coefficients indicated higher molecular interactions in ECT-PEG-400, ECT-EG, ECT-THP and ECT-PG compared with other combination of ECT with PS. The data of apparent thermodynamic analysis indicated an endothermic and entropy-driven dissolution of ECT in all PS studied. Overall, PEG-400 was found as the best solvent for solubility/miscibility of ECT compared to other solvents investigated.

Supplementary Materials: The following are available online, Figure S1: Correlation of experimental natural logarithmic solubilities $\left(\ln x_{\mathrm{e}}\right.$ ) of emtricitabine (ECT) with the van't Hoff model in various pure solvents $(P S)$ as a function of $1 / T$; symbols represent the experimental $\ln x_{\mathrm{e}}$ values of ECT and the solid lines represent the $\ln x^{\text {van't }}$ values calculated by the van't Hoff model, Figure S2: van't Hoff plots for ECT plotted between $\ln x_{\mathrm{e}}$ and $1 / T-1 / T_{\mathrm{hm}}$ for ECT in various PS, Table S1: List of materials and their properties.

Author Contributions: Conceptualization, F.S. and S.A.; methodology, N.H., I.A., F.S. and S.A.; software, F.S.; validation, N.H., I.A. and S.A.; formal analysis, I.A.; investigation, N.H., S.A., I.A. and F.S.; resources, S.A.; data curation, N.H. and I.A.; writing—original draft preparation, F.S.; writingreview and editing, N.H., I.A. and S.A.; visualization, F.S.; supervision, S.A.; project administration, F.S.; funding acquisition, S.A. All authors have read and agreed to the published version of the manuscript.

Funding: This research work was funded by Researchers Supporting Project (number RSP-2020/146) at King Saud University, Riyadh, Saudi Arabia. The APC was also funded by RSP.

Institutional Review Board Statement: Not applicable.

Informed Consent Statement: Not applicable.

Data Availability Statement: All the data associated with present manuscript have been included in supplementary materials.

Acknowledgments: Authors are thankful to Researchers Supporting Project (number RSP-2020/146) at King Saud University, Riyadh, Saudi Arabia.

Conflicts of Interest: The authors declare no conflict of interest.

Sample Availability: Samples of the compounds ECT are available from the authors. 


\section{References}

1. Ploger, G.F.; Hofsass, M.A.; Dressman, J.B. Solubility determination of active pharmaceutical ingredients which have been recently added to the list of essential medicines in the context of the biopharmaceutics classification system-biowaiver. J. Pharm. Sci. 2018, 107, 1478-1488. [CrossRef] [PubMed]

2. U.S. Department of Health and Human Services, Food and Drug Administration (FDA), Center for Evaluation and Research (CDER). Emtriva ${ }^{\circledR}$ (Emtricitabine) Capsules and Oral Solution. Guidance for Industry. Draft Guidance. Available online: https://www.accessdata.fda.gov/drugsatfda_docs/appletter/2011/021500s018,021896s015ltr.pdf (accessed on 15 February 2018).

3. Nathan, B.; Bayley, J.; Waters, L.; Post, F.A. Cobicistat: A novel pharmacoenhancer for co-formulation with HIV protease and integrase inhibitors. Infect. Dis. Ther. 2013, 2, 111-122. [CrossRef] [PubMed]

4. Siyawamwaya, M.; Toit, L.C.D.; Kumar, P.; Choonara, Y.E.; Kodiah, P.P.P.D.; Pillay, V. 3D printed, controlled release, tritherapeutic matrix tablet matrix for advanced anti-HIV-I drug delivery. Eur. J. Pharm. Biopharm. 2019, 138, 99-110. [CrossRef] [PubMed]

5. Singh, G.; Pai, R.S. Pharmacokinetics and in vivo biodistribution of optimized PLGA nanoparticulate drug delivery system for controlled release of emtricitabine. Drug Deliv. 2014, 21, 627-635. [CrossRef]

6. Srilatha, U.; Rama Krishna, M.; Vasavi Reddy, D.; Devireddy, S.R. Formulation and evaluation of emtricitabine and tinofovir disoproxil fumarate film coated tablets. Int. J. Res. Pharm. Chem. 2015, 5, 116-125.

7. Clark, M.R.; Peet, M.M.; Davis, S.; Doncel, G.F.; Friend, D.R. Evaluation of rapidly disintegrating vaginal tablets of tinofovir, emtricitabine and their combination for HIV-1 prevention. Pharm. 2014, 6, 616-631.

8. Manikandan, M.; Kannan, K.; Selvamuthukumar, S.; Manavalan, R. Formulation development and evaluation of emtricitabine and tinofovir disoproxil fumarate tablets. Int. J. Drug. Dev. Res. 2012, 4, 247-256.

9. Forbes, C.J.; McCoy, C.F.; Murphy, D.J.; Woolfson, A.D.; Moore, J.P.; Evans, A.; Shattock, R.J.; Malcolm, R.K. Modified silicone elastomer vaginal gels for sustained release of antiretroviral HIV microbicides. J. Pharm. Sci. 2014, 103, 1422-1432. [CrossRef]

10. Faria, M.J.; Machado, R.; Ribeiro, A.; Goncalves, H.; Elisabete, M.; Oliveira, C.D.R.; Viseu, T.; Neves, J.D.; Lucio, M. Rational development of liposomal hydrogels: A strategy for topical vaginal antiretroviral drug delivery in the context of HIV prevention. Pharmaceutics 2019, 11, 485. [CrossRef]

11. Fathima, A.; Hari, B.N.V.; Devi, D.R. Development of microparticulate sustained release dosage form of emtricitabine: An anti-HIV drug. Asian J. Chem. 2014, 26, 2604-2610. [CrossRef]

12. Ibrahim, I.M.; Bade, A.N.; Lin, Z.; Soni, D.; Wojtkiewicz, M.; Shetty, B.L.D.; Gautam, N.; McMillan, J.M.; Alnouti, Y.; Edagwa, B.J.; et al. Synthesis and characterization of a long-acting emtricitabine prodrug nanoformulation. Int. J. Nanomed. 2019, 14, 6231-6247. [CrossRef] [PubMed]

13. Soni, D.; Bade, A.N.; Gautam, N.; Herskovitz, J.; Ibrahim, I.M.; Smith, N.; Wojtkiewicz, M.S.; Shetty, B.L.D.; Alnouti, Y.; McMillan, J.; et al. Synthesis of a long-acting nanoformulated emtricitabine ProTide. Biomater. 2019, 222, E119441. [CrossRef] [PubMed]

14. Mandal, S.; Belshan, M.; Holec, A.; Zhou, Y.; Destache, C.J. An enhanced emtricitabine-loaded long-acting nanoformulation for prevention or treatment of HIV infection. Antimic. Agents Chemother. 2017, 61, E01475. [CrossRef] [PubMed]

15. Mandal, S.; Kang, G.; Prathipati, P.K.; Fan, W.; Li, Q.; Destache, C.J. Long-acting parenteral combination antiretroviral loaded nano-drug delivery system to treat chronic HIV-1 infection: A humanized mouse model study. Antiviral Res. 2018, 156, 85-91. [CrossRef]

16. Shakeel, F.; Haq, N.; Alsarra, I.A.; Alshehri, S. Solubility, Hansen solubility parameters and thermodynamic behavior of emtricitabine in various (polyethylene glycol-400 + water) mixtures: Computational modeling and thermodynamics. Molecules 2020, 25, 1559. [CrossRef]

17. Anwer, M.K.; Mohammad, M.; Fatima, F.; Alshahrani, S.M.; Aldawsari, M.F.; Alalaiwe, A.; Al-Shdefat, R.; Shakeel, F. Solubility, solution thermodynamics and molecular interactions of osimeritinib in some pharmaceutically useful solvents. J. Mol. Liq. 2019, 284, 53-58. [CrossRef]

18. Alanazi, A.; Alshehri, S.; Altamimi, M.; Shakeel, F. Solubility determination and three dimensional Hansen solubility parameters of gefitinib in different organic solvents: Experimental and computational approaches. J. Mol. Liq. 2020, 299, E112211. [CrossRef]

19. Kalam, M.A.; Alshamsan, A.; Alkholief, M.; Alsarra, I.A.; Ali, R.; Haq, N.; Anwer, M.K.; Shakeel, F. Solubility measurement and various solubility parameters of glipizide in different neat solvents. ACS Omega 2020, 5, 1708-1716. [CrossRef]

20. Shakeel, F.; Imran, M.; Haq, N.; Alshehri, S.; Anwer, M.K. Synthesis, characterization and solubility determination of 6-phenylpyridazin-3-(2H)-one in different pharmaceutical solvents. Molecules 2019, 24, 3404. [CrossRef]

21. Moradi, M.; Rahimpour, E.; Hemmati, S.; Martinez, F.; Barjegar-Jalali, M.; Jouyban, A. Solubility of mesalazine in polyethylene glycol 400 + water mixtures at different temperatures. J. Mol. Liq. 2020, 314, E113546. [CrossRef]

22. Soleymani, J.; Jouyban-Gharamaleki, V.; Kenndler, E.; Jouyban, A. Measurement and modeling of sodium chloride solubility in binary mixtures of water + polyethylene glycol 400 at various temperatures. J. Mol. Liq. 2020, 316, E113777. [CrossRef]

23. Alshehri, S.; Imam, S.S.; Altamimi, M.A.; Hussain, A.; Shakeel, F.; Elzayat, E.; Mohsin, K.; Ibrahim, M.; Alanazi, F. Enhanced dissolution of luteolin by solid dispersion prepared by different methods: Physicochemical characterization and antioxidant activity. ACS Omega 2020, 5, 6461-6471. [CrossRef] [PubMed]

24. Wohlfarth, C. Static Dielectric Constants of Pure Liquids and Binary Liquid Mixtures: Supplement to IV/6; Springe: New York, NY, USA, 2008; Volume 17.

25. Dannhauser, W.; Cole, R.H. Dielectric properties of liquid butyl alcohols. J. Phys. Chem. 1955, 23, 1762-1766. [CrossRef] 
26. Shirke, R.M.; Chaudhari, A.; More, N.M.; Patil, P.B. Temperature dependent dielectric relaxation study of ethyl acetate-alcohol mixtures using time domain technique. J. Mol. Liq. 2001, 94, 27-36. [CrossRef]

27. Romani, D.; Brandan, S.A. Investigating the structural and vibrational properties of the nucleoside reverse transcriptase inhibitor emtricitabine. Int. J. Sci. Res. Method 2017, 8, 236-277.

28. Van Krevelen, D.W.; te Nijenhuis, K. Properties of Polymers: Their Correlation with Chemical Structure; Their Numerical Estimation and Prediction from Additive Group Contributions; Elsevier: Amsterdam, The Netherland; Tokyo, Japan, 2009; p. 189.

29. Güner, A. The algorithmic calculations of solubility parameter for the determination of interactions in dextran/certain polar solvent systems. Eur. Polym. J. 2004, 40, 1587-1594. [CrossRef]

30. Mohammad, M.A.; Alhalaweh, A.; Velaga, S.P. Hansen solubility parameter as a tool to predict cocrystal formation. Int. J. Pharm. 2011, 407, 63-71. [CrossRef]

31. Greenhalgh, D.J.; Williams, A.C.; Timmins, P.; York, P. Solubility parameters as predictors of miscibility in solid dispersions. J. Pharm. Sci. 1999, 88, 1182-1190. [CrossRef]

32. Apelblat, A.; Manzurola, E. Solubilities of o-acetylsalicylic, 4-aminosalicylic, 3,5-dinitrosalicylic and p-toluic acid and magnesiumDL-aspartate in water from T $=(278-348)$ K. J. Chem. Thermodyn. 1999, 31, 85-91. [CrossRef]

33. Manzurola, E.; Apelblat, A. Solubilities of L-glutamic acid, 3-nitrobenzoic acid, acetylsalicylic, p-toluic acid, calcium-L-lactate, calcium gluconate, magnesium-DL-aspartate, and magnesium-L-lactate in water. J. Chem. Thermodyn. 2002, 34, 1127-1136. [CrossRef]

34. Ksiazczak, A.; Moorthi, K.; Nagata, I. Solid_solid transition and solubility of even n-alkanes. Fluid Phase Equilib. 1994, 95, 15-29. [CrossRef]

35. Tong, Y.; Wang, Z.; Yang, E.; Pan, B.; Jiang, J.; Dang, P.; Wei, H. Determination and correlation of solubility and solution thermodynamics of ethenzamide in different pure solvents. Fluid Phase Equilib. 2016, 427, 549-556. [CrossRef]

36. Shakeel, F.; Alshehri, S.; Imran, M.; Haq, N.; Alanazi, A.; Anwer, M.K. Experimental and computational approaches for solubility measurement of pyridazinone derivative in binary (DMSO + water) systems. Molecules 2020, 25, 171. [CrossRef]

37. Kalam, M.A.; Alshehri, S.; Alshamsan, A.; Alkholief, M.; Ali, R.; Shakeel, F. Solubility measurement, Hansen solubility parameters and solution thermodynamics of gemfibrozil in different pharmaceutically used pure solvents. Drug Dev. Ind. Pharm. 2019, 45, 1258-1264. [CrossRef] [PubMed]

38. Shakeel, F.; Haq, N.; Alshehri, S.; Ibrahim, M.A.; Elzayat, E.M.; Altamimi, M.A.; Mohsin, K.; Alanazi, F.K.; Alsarra, I.A. Solubility, thermodynamic properties and solute-solvent molecular interactions of luteolin in various pure solvents. J. Mol. Liq. 2018, 255, 43-50. [CrossRef]

39. Higuchi, T.; Connors, K.A. Phase-solubility techniques. Adv. Anal. Chem. Instr. 1965, 4, 117-122.

40. Kitak, T.; Dumicic, A.; Planinsek, O.; Sibanc, R.; Srcic, S. Determination of solubility parameters of ibuprofen and ibuprofen lysinate. Molecules 2015, 20, 21549-21568. [CrossRef]

41. Kato, Y.; Osawa, T.; Yoshihara, M.; Fujii, H.; Tsutsumi, S.; Yamamoto, H. Evaluation of the antifoaming effect using Hansen, Hansen solubility parameters. ACS Omega 2020, 5, 5684-5690. [CrossRef]

42. Altamimi, M.; Haq, N.; Alshehri, S.; Qamar, W.; Shakeel, F. Enhanced skin permeation of hydrocortisone using nanoemulsion as potential vehicle. ChemistrySelect 2019, 4, 10084-10091. [CrossRef]

43. Ruidiaz, M.A.; Delgado, D.R.; Martínez, F.; Marcus, Y. Solubility and preferential solvation of indomethacin in 1,4-dioxane + water solvent mixtures. Fluid Phase Equilib. 2010, 299, 259-265. [CrossRef]

44. Hildebrand, J.H.; Prausnitz, J.M.; Scott, R.L. Regular and Related Solutions; Van Nostrand Reinhold: New York, NY, USA, 1970.

45. Manrique, Y.J.; Pacheco, D.P.; Martínez, F. Thermodynamics of mixing and solvation of ibuprofen and naproxen in propylene glycol + water cosolvent mixtures. J. Sol. Chem. 2008, 37, 165-181. [CrossRef]

46. Xu, H.; Kang, L.; Qin, J.; Lin, J.; Xue, M.; Meng, Z. Solubility of azilsartan in methanol, ethanol, acetonitrile, n-propanol, isopropanol, tetrahydrofuran, and binary solvent mixtures between 293. 15 and $333.15 \mathrm{~K}$. ACS Omega 2020, 5, 6141-6145. [CrossRef] [PubMed]

47. Holguín, A.R.; Rodríguez, G.A.; Cristancho, D.M.; Delgado, D.R.; Martínez, F. Solution thermodynamics of indomethacin in propylene glycol + water mixtures. Fluid Phase Equilib. 2012, 314, 134-139. [CrossRef]

48. Krug, R.R.; Hunter, W.G.; Grieger, R.S. Enthalpy-entropy compensation. 2. Separation of the chemical from the statistic effect. J. Phys. Chem. 1976, 80, 2341-2351. [CrossRef] 